\title{
Participation Determinants in the DRG Payment System of Obstetrics and Gynecology Clinics in South Korea
}

\author{
Jung-Kook Song*, Chang-yup Kim \\ Graduate School of Public Health, Seoul National University
}

\begin{abstract}
Objectives: The Diagnosis Related Group (DRG) payment system, which has been implemented in Korea since 1997, is based on voluntary participation. Hence, the positive impact of this system depends on the participation of physicians. This study examined the factors determining participation of Korean obstetrics \& gynecology (OBGYN) clinics in the DRG-based payment system.

Methods: The demographic information, practice-related variables of OBGYN clinics and participation information in the DRG-based payment system were acquired from the nationwide data from 2002 to 2007 produced by the National Health Insurance Corporation and the Health Insurance Review \& Assessment Service. The subjects were 336 OBGYN clinics consisting of 43 DRG clinics that had maintained their participation in 2003-2007 and 293 no-DRG (fee-for-service) clinics that had never been a DRG clinic during the same period. Logistic regression analysis was carried out to determine the factors associated with the participation of OBGYN clinics in the DRG-based payment system.

Results: The factors affecting participation of OBGYN clinics in the DRG-based payment system were as follows $(p<0.05)$ : (1) a larger number of caesarian section (c/sec) claims, (2) higher cost of a c/sec, (3) less variation in the price of a c/sec, (4) fewer days of admission for a c/sec, and (5) younger pregnant women undergoing a c/sec.

Conclusions: These results suggest that OBGYN clinics with an economic practice pattern under a fee-for-service system are more likely to participate in the DRG-based payment system. Therefore, to ensure adequate participation of physicians, a payment system with a stronger financial incentive might be more suitable in Korea.
\end{abstract}

Key words: Determinants, Korea, Payment system

J Prev Med Public Health 2010;43(2):117-124

\section{INTRODUCTION}

The uncertainty of diagnosis or treatment in medical services explains the inevitable practice-related variations (professional uncertainty hypothesis) [1]. However, social issues can be raised when the practicerelated variables are interconnected with the increased volume of medical services provision. The fee-forservice payment system, which guarantees medical revenues from service provision, has amplified physicians' practice-related variations by this economic inducement $[2,3]$. Moreover, there has been some criticism that this payment system is the major cause of the increasing national health expenditure. On the other hand, The DRG-based payment system is designed to have no association between an increase in medical treatment and additional profits. This can lead physicians to reduce the medical treatment to the minimum level possible and simultaneously decrease the practicerelated variations [4]. For this reason, the DRG-based payment system has been adopted in many nations including the United States as a solution for budget constraint.

In 1994, a government committee for Korean healthcare reform expected that a DRG-based payment system would decrease the cost of medical services and provide a rationalized medical fee schedule together with a decrease in out-of-pocket expenses. The existing Korean fee-for-service payment system could not find answer to these problems [5-7]. At that time, the fee-forservice payment system was performed by taking every single service as a payment unit. There were considerable difficulties in setting the individual medical fee schedule with a balance of fee schedule between medical services. It was also extremely difficult to make an annual increase in rate. Korean physicians reacted to this payment system in a distorted way of service provision, concentrating investment in service items with relatively high profit or developing items outside the national health insurance coverage [8]. Here, the conflicting opinion towards the level of the medical fee schedule between the insurer and physicians is because revenue generation is impossible when only reimbursement by the national health 
insurance coverage is calculated. However, it is possible to guarantee a certain level of profit when a calculation of outside reimbursement is included. As the insurer lowers the medical fee schedule, the physicians must increase the portion of items outside the national health insurance coverage. Therefore, a rationalized medical fee schedule will have a decreasing effect on out-of-pocket expenses. The Korean DRG-based payment system covers MRI, ultrasound, the fee for provider selection, ward with better amenity, and patient food with higher quality (these five items are outside the national health insurance coverage), and all the services excluding several 100/100 items. This system was introduced in 1997, and in 2009, it is implemented in 7 disease groups - such as cataract, tonsillectomy and adenoidectomy, appendectomy, hemorrhoids, hernia, hysterectomy and cesarean section, under 4 clinical departments (ophthalmology, otorhinolaryngology, general surgery, and obstetrics \& gynecology).

Since the Korean DRG-based payment system is based on voluntary participation, the positive impact from this system depends on the participation of physicians. Therefore, it is worthwhile to examine the factors that affect the physicians' decision to participate in a DRG-based payment system. There have been several studies on the factors affecting physicians' decision to participate in a newly adopted system. Sloan and Steinwald's "the economic two market model" explains that there is a private market that sets the price and a public market that takes the decided price for physicians [9]. Physicians are unlikely to participate in the public market when the price of the private market is higher than that of the public market. It was reported that from the relationship between participation in the Blue shield and demand variables (number of potential patients, regional income level, number of physician per unit demographic, specialty, extra earnings), cost function variables (cost of personnel, medical fee schedule), and insurance variables (participation patterns), the economic contributories were found to be primary affecting variables for the decision to participate in Medicaid, and the characteristics of physicians were also found to affect the decision. From the same theory, Sloan [10] examined the nationwide survey data and claimed that if the medical fee schedule for Medicaid is high and if burden of administration is low, the United States private-practice physicians under the fee-forservice payment system would participate in Medicaid and future U.S.A universal NHI program. Lately, the model by Silverstein and Kirkman-Liff analyzed on the major variables of former studies but also analyzed the attitude of physicians towards Medicaid-type patients and their level of satisfaction with Medicaid managed care. They concluded that the actual price level together with the value given by the physicians acted as essential factors in their decision [11]. This study was carried out as there has been no research on the factors determining the participation in a DRG-based payment system in Korea. The major variables confirmed from the above former studies were used as variables. The aim of this study was to determine the factors that helped Korean OBGYN clinics to decide to participate in the DRGbased payment system, and what policy implications could enhance participation. The reason for selecting OBGYN clinics from the 4 clinical departments of the DRG-based payment system is because the 2007 participation data revealed participation rates of $99 \%$ by ophthalmology, $85 \%$ by general surgery, $57 \%$ by OBGYN, and $38 \%$ by Otorhinolaryngology. OBGYN was expected to be better than the other clinical departments with a much higher or lower participation in securing samples for participation and non-participation with balance.

\section{SUBJECTS AND METHODS}

\section{Subjects}

The OBGYN clinics providing Caesarean operation since 2002 until 2007 for six years were selected from the records of the Health Insurance Review and Assessment Service. A total of 43 OBGYN clinics participating in the DRG-based payment system in 2007 and made the decision to participate between 2003-2007 were selected. These clinics were obtained by excluding 55 clinics with only 1 claim from the past participation year or with the same year of opening and starting year for participation, and 153 clinics that had no changes in participation since 2002 until 2007 from the 251 clinics with claims for Caesarean operations while participating in the DRG-based payment system in 2007. The clinics continually participating after new participation and reparticipating clinics after secession were included because participation changes are possible in every year. When the continual participation of participant term was analyzed by the process of tracing back to year of 2007 , there were 10 clinics with 1 year of participation, 8 clinics with 2 years, 15 clinics with 3 years, 7 clinics with 4 years and 3 clinics with 5 years of participation. For the Non-participants, there were a total of 293 OBGYN clinics nationwide, which had never 


\begin{tabular}{|c|c|c|c|c|c|c|c|c|c|c|}
\hline & 2001 & 2002 & 2003 & 2004 & 2005 & 2006 & 2007 & $n$ & $n$ & $n$ \\
\hline DRG/PY6 $\leq$ & 1 & 1 & 1 & 1 & 1 & 1 & 1 & \multirow{10}{*}{251} & 153 & \\
\hline DRG/PY5 & 0 & 0 & 1 & 1 & 1 & 1 & 1 & & $9(6)$ & 3 \\
\hline \multirow[t]{2}{*}{ DRG/PY4 } & 0 & 0 & 0 & 1 & 1 & 1 & 1 & & $15(12)$ & 3 \\
\hline & $1 / 0$ & $1 / 0$ & 0 & 1 & 1 & 1 & 1 & & $4(0)$ & 4 \\
\hline \multirow[t]{2}{*}{ DRG/PY3 } & 0 & 0 & 0 & 0 & 1 & 1 & 1 & & $24(11)$ & 13 \\
\hline & $1 / 0$ & $1 / 0$ & $1 / 0$ & 0 & 1 & 1 & 1 & & $2(0)$ & 2 \\
\hline \multirow[t]{2}{*}{ DRG/PY2 } & 0 & 0 & 0 & 0 & 0 & 1 & 1 & & $21(14)$ & 7 \\
\hline & $1 / 0$ & $1 / 0$ & $1 / 0$ & $1 / 0$ & 0 & 1 & 1 & & $2(1)$ & 1 \\
\hline \multirow[t]{3}{*}{ DRG/PY1 } & 0 & 0 & 0 & 0 & 0 & 0 & 1 & & $18(10)$ & 8 \\
\hline & $1 / 0$ & $1 / 0$ & $1 / 0$ & $1 / 0$ & $1 / 0$ & 0 & 1 & & $3(1)$ & 2 \\
\hline & & & & & & & & & $98(55)$ & 43 \\
\hline FFS & $1 / 0$ & $1 / 0$ & $1 / 0$ & $1 / 0$ & $1 / 0$ & $1 / 0$ & 0 & \multirow{2}{*}{338} & 31 & \\
\hline FFS & 0 & 0 & 0 & 0 & 0 & 0 & 0 & & $307(14)$ & 293 \\
\hline & & & & & & & & 589 & 589 & 336 \\
\hline
\end{tabular}

Figure 1. Distribution of the subjects according to the participation status.

FFS: Fee-for-service clinics, DRG: DRG clinics, PY: Participation Year, 1: participation, 0: no participation.

participated. These clinics were applied to the 338 clinics nationwide that were not participating in the DRG-based payment system in 2007, along with the records of Caesarean operations with the following feefor-service payment system since 2002 until 2007 with more than 2 claims.

The variables (annual number of claims for Caesarean operations, average price of Caesarean operations, average number of admission days of Caesarean operation, average patient age for Caesarean operation) related to the medical treatment by OBGYN clinics were obtained by analyzing a total of 27288 Caesarean operation claims with a severity ' 0 ' case excluding Medical aid by the 336 researched clinics. For the participating group, the previous year data on participation decision, the total amount of medical treatment fee under the fee-for-service system (reviewed by the Health Insurance Review and Assessment Service) was revised using the fee schedule for 2007 , and the non-participating groups were set using the claims for 2007 so that both groups would not be exposed to the DRG-based payment system during the comparison. On the other hand, information, such as the total number of sick beds in the clinic, number of specialists in OBGYN clinics, age and gender of the representative was acquired from the relevant year data at the National Health Insurance Corporation. The analysis unit of this research is a clinic.

\section{Variables}

The participation in a DRG-based payment system by a clinic was set as the dependent variable, and the other factors that could be related to it were set as the independent variables. The dependent variable was classified as participation and non-participation as at December 31st 2007. The gender and age of the representative that explained the demographic and social characteristics of the physicians in 2007, number of OBGYN specialists per clinic in the relevant year, and total number of sick beds were set as the independent variables. Overall, 7 clinical related variables were selected. In order to control the severity and social economic factors of patients between clinics, the clinical related variables were calculated only using the claims of Caesarean operations with a severity ' 0 ' , excluding the relevant year claims of Medical aid [12]. The following 7 items were considered: 1) the relevant year annual number of Caesarean operations; 2) the adjusted Caesarean operation medical fee in 2007; 3) the average admission days of Caesarean operations as a level of resource input by the physician; 4) and 5) the coefficient of variation in the price of a Caesarean operation and the coefficient of variation in the admission days of a Caesarean operation as a level of standardization of treatment, respectively; 6) the average age of the patients undergoing a Caesarean operation as risk aversion by the physician; and 7) the coefficient of variation in patient age in Caesarean operation. The average patient age was seen as a clinical related variable because almost without exception, expectant mothers usually show good compliance with the suggestion of physicians when they are advised to give birth in a superior medical institution for specific medical reasons.

\section{Statistical Analysis}

All statistical analyses were performed using SAS 
Table 1. Characteristics of fee-for-service clinics and DRG clinics

\begin{tabular}{|c|c|c|c|c|}
\hline \multirow{2}{*}{ Factors } & \multirow{2}{*}{$\begin{array}{c}\text { Total }(\mathrm{n}=336) \\
\mathrm{n}(\%)\end{array}$} & \multirow{2}{*}{$\frac{\mathrm{FFS}(\mathrm{n}=293)}{\mathrm{n}(\%)}$} & \multirow{2}{*}{$\begin{array}{c}\text { DRG }(n=43) \\
n(\%)\end{array}$} & \multirow{2}{*}{$p$-value } \\
\hline & & & & \\
\hline Gender of representative & & & & 0.429 \\
\hline Male & $301(89.6)$ & $261(89.1)$ & $40(93.0)$ & \\
\hline Female & $35(10.4)$ & $32(10.9)$ & $3(7.0)$ & \\
\hline Age of representative $\pm \mathrm{SD}$ (y) & $45.4 \pm 6.9$ & $45.4 \pm 6.7$ & $45.7 \pm 8.2$ & 0.789 \\
\hline Age group of representative (y) & & & & 0.591 \\
\hline$<40$ & $62(18.5)$ & $54(18.4)$ & $8(18.6)$ & \\
\hline $40-49$ & $202(60.1)$ & $179(61.1)$ & $23(53.5)$ & \\
\hline $50-59$ & $59(17.6)$ & $50(17.1)$ & $9(20.9)$ & \\
\hline$\geq 60$ & $13(3.9)$ & $10(3.4)$ & $3(7.0)$ & \\
\hline Number of OBGYN specialist \pm SD (person) & $2.0 \pm 1.4$ & $2.0 \pm 1.4$ & $2.3 \pm 1.3$ & 0.098 \\
\hline Number of OBGYN specialist (person) & & & & 0.018 \\
\hline 1 & $162(48.2)$ & $149(50.9)$ & $13(30.2)$ & \\
\hline 2 & $86(25.6)$ & $74(25.3)$ & $12(27.9)$ & \\
\hline$\geq 3$ & $88(26.2)$ & $70(23.9)$ & $18(41.9)$ & \\
\hline Number of total sick bed & $12.0 \pm 8.1$ & $11.7 \pm 8.0$ & $13.7 \pm 8.5$ & 0.144 \\
\hline Volume of C/Sec $\pm \mathrm{SD}$ (No. of claims) & $81 \pm 117$ & $73 \pm 102$ & $131 \pm 185$ & 0.002 \\
\hline Volume of $\mathrm{C} / \mathrm{Sec}$ (No. of claims) & & & & 0.031 \\
\hline$<80$ & $233(69.4)$ & 209 (71.3) & $24(55.8)$ & \\
\hline$<240$ & 78 (23.2) & $66(22.5)$ & $12(27.9)$ & \\
\hline$\geq 240$ & $25(7.4)$ & $18(6.1)$ & $7(16.3)$ & \\
\hline Price of $\mathrm{C} / \mathrm{Sec} \pm \mathrm{SD}$ in KRW $w 10000$ & $77.4 \pm 8.6$ & $76.6 \pm 8.2$ & $83.0 \pm 9.3$ & $<0.001$ \\
\hline Price of C/Sec in KRW $w 10000$ & & & & $<0.001$ \\
\hline$<80$ & $217(64.6)$ & $198(67.6)$ & $19(44.2)$ & \\
\hline$<90$ & $100(29.8)$ & $83(28.3)$ & $17(35.5)$ & \\
\hline$\geq 90$ & $19(5.6)$ & $12(4.1)$ & $7(16.3)$ & \\
\hline $\mathrm{CV}$ in Price of $\mathrm{C} / \mathrm{Sec} \pm \mathrm{SD}$ & $11.7 \pm 4.4$ & $11.8 \pm 4.4$ & $10.8 \pm 4.5$ & 0.153 \\
\hline Admission days of $\mathrm{C} / \mathrm{Sec} \pm \mathrm{SD}$ & $6.7 \pm 0.8$ & $6.7 \pm 0.8$ & $6.6 \pm 0.8$ & 0.377 \\
\hline Admission days of $\mathrm{C} / \mathrm{Sec}$ & & & & 0.250 \\
\hline$<6.6$ & $148(44.1)$ & $124(42.3)$ & $24(55.8)$ & \\
\hline$<7.6$ & $147(43.8)$ & $132(45.1)$ & $15(34.9)$ & \\
\hline$\geq 7.6$ & $41(12.2)$ & $37(12.6)$ & $4(9.3)$ & \\
\hline $\mathrm{CV}$ in Admission days of $\mathrm{C} / \mathrm{Sec} \pm \mathrm{SD}$ & $13.5 \pm 9.2$ & $13.5 \pm 9.2$ & $13.6 \pm 8.7$ & 0.903 \\
\hline Patient age of C/Sec \pm SD (y) & $31.0 \pm 1.6$ & $31.1 \pm 1.5$ & $30.0 \pm 1.7$ & $<0.001$ \\
\hline Patient age of $\mathrm{C} / \mathrm{Sec}$ & & & & $<0.001$ \\
\hline$<30$ & $68(20.2)$ & $46(15.7)$ & $22(51.2)$ & \\
\hline$<32$ & $197(58.6)$ & $127(61.1)$ & $18(41.9)$ & \\
\hline$\geq 32$ & $71(21.1)$ & 68 (23.2) & $3(7.0)$ & \\
\hline $\mathrm{CV}$ in Patient age of $\mathrm{C} / \mathrm{Sec}$ & $12.5 \pm 3.6$ & $12.5 \pm 3.6$ & $12.4 \pm 3.5$ & 0.775 \\
\hline Total & $336 \quad 100$ & $293 \quad 100$ & $43 \quad 100$ & \\
\hline
\end{tabular}

OBGYN: obstetrics \& gynecology, FFS : Fee-For-Senvice clinics, DRG:DRG clinics, KRW : Korean Won, CV : Coefficient of Variation, C/Sec : Caesarian section.

version 9.1 (SAS Inc., Cary, NC, USA). Frequency analysis was used to examine the distributions of the independent variables, and t-test and chi-square analysis were used to analyze the demographic and social variables (gender, age, number of OBGYN specialists per clinic, total number of sick beds) and medical related variables (relevant year annual number of Caesarean operations, the adjusted Caesarean operation medical fee in 2007, average admission days of a Caesarean operation, average patient age for a Caesarean operation and each coefficient of variation in the last three variables) to determine the differences between the participating group and non-participating group for DRG-based payment system.

The multicollinearity between independent variables was verified by correlation analysis. The determinants in the participation of the DRG-based payment system by the OBGYN clinic were selected by logistic regression analysis, and the adequacy of the fit for an acquired model was analyzed using a Hosmer-Remshaw goodness-of-fit test.

\section{RESULTS}

\section{I . Descriptive Analysis}

The general characteristics of the 336 researched OBGYN clinics were investigated (Table 1). Forty-three 
Table 2. Correlation matrix

\begin{tabular}{|c|c|c|c|c|c|c|c|c|c|c|}
\hline & Drage & Bed & Obgyp & Vol & Price & Cv_price & Adm & Cv_adm & Ptage & Cv_ptage \\
\hline Drage & 1.00 & & & & & & & & & \\
\hline Bed & 0.09 & 1.00 & & & & & & & & \\
\hline Obgyp & 0.00 & $0.62^{*}$ & 1.00 & & & & & & & \\
\hline Vol & 0.02 & $0.50^{\star}$ & $0.62^{*}$ & 1.00 & & & & & & \\
\hline Price & 0.01 & $0.16^{\star}$ & $0.14^{*}$ & 0.05 & 1.00 & & & & & \\
\hline Cv_price & 0.00 & 0.08 & 0.11 & $0.13^{*}$ & 0.00 & 1.00 & & & & \\
\hline $\mathrm{Adm}$ & $0.17^{\star}$ & $0.15^{\star}$ & 0.10 & -0.09 & $0.52^{\star}$ & $-0.21^{*}$ & 1.00 & & & \\
\hline Cv_adm & -0.07 & 0.08 & 0.08 & 0.00 & $-0.13^{*}$ & $0.05^{*}$ & $-0.22^{*}$ & 1.00 & & \\
\hline Ptage & $0.22^{*}$ & -0.04 & -0.10 & $-0.12^{*}$ & -0.10 & -0.05 & -0.22 & -0.01 & 1.00 & \\
\hline Cv_ptag & -0.03 & -0.08 & -0.12 & -0.07 & -0.09 & 0.09 & 0.08 & 0.07 & -0.27 & 1.00 \\
\hline
\end{tabular}

Drage : Age of representative, Bed : Number of total sick beds, Obgyp : Number of OBGYN specialist, Vol : Volume of C/S, Price : Price of a C/S Cv_price : Coefficient of variation in price of a C/S, Adm : Admission days of a C/S, Cv_adm : Coefficient of variation in admission days of a C/S, Ptage : Patient age of C/S, Cv_ptage : Coefficient of variation in patient age of C/S. ${ }^{*} \mathrm{p}<0.05$

$(12.3 \%)$ clinics were participating in the DRG-based payment system presently in 2007 and $293(87.2 \%)$ clinics were not. First, when the demographic social variables were considered, there was no significant difference in the gender ratio and average age distribution between the participating and nonparticipating representatives. The number of specialists per clinic and total number of sick beds that presents the scale of the clinic were not shown to be significant. The average number of specialists per clinic was $2.0 \pm 1.4$, and the average total number of sick beds was $12 \pm 8.1$.

The average number of annual Caesarean operations was 81 . The average number of operations for the participating group was 131 , which is considerably higher than the average of 73 operations by nonparticipating groups when the medical related variables were considered. This can also be verified in number of distribution cases by the physicians under research, approximately $44 \%$ in the participating group and only $28 \%$ by non-participating groups were relevant. The price of a Caesarean operation in both groups was also different. The total cost was calculated to be 774000 Won; 830000 Won in the participating group and 766 000 Won in the non-participating group. The percentage of claims where the total cost was over 900000 Won was $5.6 \% ; 16.3 \%$ in the participating group and $4.1 \%$ in the non-participating group. The coefficient of variation per medical cost that showed the variable of volume of medical service in a fee-for-service system was similar in the two groups. The average total admission days of the Caesarean operations were $6.7 \pm 0.8$, which was similar in the two groups. The coefficient of variation for the number of admission days, and the other variable that can show differences in the volumes of medical service was also similar in the two groups. Finally, the average age of a patient undergoing a Caesarean operation was $31 \pm 1.6 ; 30.0 \pm 1.7$ and $31.1 \pm 1.5$ in the participating and non-participating groups, respectively, showing statistical significance. The percentage of patients under 30 years of age was $51.2 \%$ and $15.7 \%$ in the participating and non-participating group, respectively, showing statistical significance. However, the coefficient variation for the patient age was similar in the two groups.

\section{Multivariate Analysis}

The relationship between the variables that affect the participation in the DRG-based payment system was calculated using Pearson's correlation coefficient and Spearman's rank correlation coefficient for the continuous variables and categorical variables Otorhinolaryngology, respectively. The correlation coefficient between the number of total sick beds and number of OBGYN specialists were 0.62 , which was the highest value (Table 2). The actual multicollinearity was controlled by a model establishment utilizing the variable selection procedure.

The dependent variable was determined to be participation in a DRG-based payment system. Age, gender of the representatives, number of specialists in the OBGYN clinic, number of sick beds in the OBGYN clinic, and the 7 medical related variables were used as independent variables for logistic regression analysis (Table 3). This model showed no significant distinction between the predictive value and observation value according to the Hosmer-Lemeshow goodness-to-fit test. The annual number of Caesarean operations, medical fee for Caesarean operation, coefficient of variation of Caesarean operation fee, number of admission days by Caesarean operation, and average patient age of Caesarean operation, were all found to be significant. 
Table 3. Logistic regression for voluntary participation in the DRG-based payment system by obstetrics \& gynecology clinics

\begin{tabular}{clccr}
\hline Step & \multicolumn{1}{c}{ Effect } & OR & $95 \%$ Cl & p-value \\
\hline 1 & Volume of C/Sec (10 claims) & 1.03 & $1.005-1.057$ & 0.02 \\
2 & Price of C/Sec (KRW $\# 10000)$ & 1.14 & $1.082-1.198$ & $<0.01$ \\
3 & CV in Price of C/Sec & 0.86 & $0.776-0.947$ & $<0.01$ \\
4 & Admission days of C/Sec (d) & 0.33 & $0.180-0.589$ & $<0.01$ \\
5 & Patient age of C/Sec (y) & 0.56 & $0.428-0.718$ & $<0.01$ \\
\hline
\end{tabular}

$\mathrm{CV}$ : coefficient of variation [CV $=$ standard deviation $/$ mean $\times 100$ ] OR : odds ratio, $\mathrm{Cl}$ : confidence interval, C/Sec: casearean.

The annual number of Caesarean operations and the medical fee for Caesarean operations were associated with the likelihood of participation. On the other hand, the coefficient of variation of a Caesarean operation fee, number of admission days of Caesarean operation, and average patient age of a Caesarean operation were not associated with participation.

The odds in participating in the DRG-based payment system was 1.03 times higher when the number of annual Caesarean operations was increased by 10 cases. Moreover, the odds in participating in the DRG-based payment system was 1.14 times higher when the medical fee for a Caesarean operation was increased by 10000 Won. On the other hand, the odds in participating in DRG-based payment system was 0.86 times lower when the coefficient of variation of Caesarean operation fee rises by 1 , and 0.33 times lower when number of admission days was increased by one day. In addition, odds in participating in DRG-based payment system was 0.56 times lower when the average patient age was increased by 1 year.

The results of only the clinics participating in a DRGbased payment system without ceasing as a participating group $(n=34)$ were similar to those in the participation group $(n=43)$ including the clinics that had seceded and later re-participated in the system.

\section{DISCUSSION}

The higher the proportion of reimbursement for DRG's diseases was in the total reimbursement, the higher the participation rate of medical institutions of clinic level was in the DRG-based payment system in 2007. The proportion with the participation rate in 2007 ranged from $0.2 \%$ (1009/462 759 million Won) with $38.2 \%$ in otorhinolaryngology, 10.1\% (37 211/351 687 million Won) with 58\% in OBGYN, 35.2\% (96699/275 062 million Won) with $85.9 \%$ in general surgery to $34.1 \%$ (167 135/489620 million Won) with $99.9 \%$ in ophthalmology. On the other hand, the same year's proportion of the clinics providing medical services for DGR' s diseases in medical institutions of clinic level ranged from $7 \%$ (136/1844 cases) in otorhinolaryngology, 33\% (572/1737 cases) in OBGYN, 60\% (636/1059 cases) in general surgery to $69 \%(867 / 1265$ cases $)$ in ophthalmology. $[8,13]$.

There was no coherence in the research results towards different practice patterns and productivity by female and male practitioners [14]. In this study, the gender of the representatives of the clinics was not associated with the participation in a DRG system.

The doctor's age was associated with the different applications in admission treatment standards towards new born babies according to the doctor's standards or by the utilization of diverse diagnosis services among doctors $[15,16]$. One study reported that doctors with 20 29 years of practice experiences had the highest monthly average income [17]. In addition, 40 50 years old doctors had a higher tendency to order more admission days and medication days $[18,19]$. Therefore, when the age of representative is very high or low, an assumption was made that their participation in the DRG-based payment system would be lower because they are much less sensitive to economic incentives but the analysis results showed no significant statistical distinctions.

There were no coherent relationships between the participation and the number of specialists in OBYGN clinics. There is the expectation that participation would increase when the standardization of medical services provision is simply achieved by economic inducement, such that there are a smaller number of specialists or another expectation that as the number of specialists increase, their share of their total medical profit would decrease, which would bring economic inducement to decrease their revenues, or even a theory that an incentive policy is effective in an individualism culture [20]. However, none of these elements supported the results.

The annual revenue obtained by Caesarean operations is a multiple of the annual total cases and medical fee per cases. Here, both the cases and medical fee has a positive effect on profit. In addition, the DRG-based payment system is designed to achieve profit by reducing medical resource consumption through the standardization of medical services provision. Therefore, by the logistic regression analysis results, the number of annual Caesarean operation cases, the medical fee of Caesarean operation, coefficient of variation in Caesarean operation of medical fee, admission days of Caesarean operation, and average patient age of 
Caesarean operation were suitable for selection as statistically significant determinants. In this study, the coefficient of variation in Caesarean operation medical fee and the coefficient of variation in admission days for Caesarean operation were examined based on preceding research [21], which analyzed the variation coefficient towards the number of treatments for outside insurance coverage items, rate of medical fee for outside insurance coverage items, number of services, intensity of services, total number of treatments, total volume of medical fee, and admission days per disease group for variation towards the consumption of medical resources.

The average age of the patients undergoing Caesarean operation with a severity ' 0 ' in the participating and nonparticipating group was 30.0 years old and 31.1 years, respectively, which was statistically significant. However, there was no distinction between these two groups because those mothers were under 35 years of age which is classified as a high risk group by the obstetricians [22].

The appearance of odds over 1 in a Caesarean operation from the logistic regression analysis model conflicts with the results reported by Sloan and Steinwald towards the participation in the Blue Shield by American physicians. The physicians located in high income areas or treating relatively wealthy patients in U.S.A. reported that participation in the insurance was less because the medical price level determined by the insurer was unsatisfactory [10]. With this, the odds can be interpreted that economically sensitive providers among OBGYN clinics reacted towards the economic inducement of the DRG-based payment system. As positive effects of adopting the DRG-based payment system in Korea, there are studies [5,23-25] showing that physicians reduced medical services provision for admission patients. However, the results showed that physicians who already avoided risk by selecting patient age, with relatively short admission days and less variation in medical fee actively participated in the DRG-based payment system. This also appears to support the above description.

It was previously reported [26] that the higher proportion of revenue by the prospective payment system in a total physician's revenue showed the more behavioral changes in medical practice after participation [27]. In that sense, physicians were expected to participate if the revenue from Caesarean operations was guaranteed to a certain level. Indeed, the claims data from the Health Insurance Review and Assessment Service reported that the number of OBGYN clinics that performed delivery services in
2002 was 831 , which was reduced to only 589 in 2007 , showing an annual decrease of 6 9\%. However, OBGYN clinics maintained the volume of Caesarean operations at 75 100 cases per year. As there was no ways to determine the total medical revenue of OBGYN clinics, it was unable to verify the accordance with previous studies. Nevertheless, the fact that level of medical fee of non-participating clinics was low and that cases of medical treatment (average of 73 cases), which was almost half that of participating clinics (average of 131 cases), suggested that the weight of medical revenue preserved by the DRG-based payment system in a total medical revenue of the nonparticipating group was too insignificant to attract them.

For the purpose of comparability and causality, the payment system should be identical in the two groups, participating group and non-participating group, when the Caesarean operation medical fee was analyzed. In other words, an adjustment of the medical fee was carried out by determining the conversion value of 2007 through the application of the compound annual increase rates of the National Health Insurance. The data for the participating group was from the previous fiscal year of continuous participation, and the data for the nonparticipating group was from 2007 under fee-for-service system. However, there were not any adjustments for changes over time in the provider's practice patterns. Even though this research examined important factors related to provider-sided determinants of participation, administrative costs, practice environment, and the values by OBGYN specialist were not considered. This can be another limit. However, this research has strength from the date that guarantees consistency and objectivity.

The determinants affecting participation in the DRGbased payment system were closely related to economic inducement rather than the socio-demographic characteristics of physicians. At first, efforts were made to find other determinants than economic inducement that would explain the inactive participation by OBGYN clinics but no other elements were found. The fact that OBGYN clinics which were more sensitive to economic inducement under a fee-for-service system were more likely to participate in the DRG-based payment system in Korea suggests that a payment system with a stronger financial incentive will be effective in motivating the providers to create cost conscious practice patterns in Korea. If a policy plans to expand the number of OBGYN clinics partaking in delivery, and to motivate them to participate in the DRG-based payment system, the proportion of DRG diseases occupation in the total reimbursement must increase to at least a similar level to 
ophthalmology or general surgery (approximately 30\%), which would be another solution. To do so, practical considerations should be given to include new disease groups into the system or guarantee the number of delivery cases that secures an economy of scale. The overall determinants for participation in the Korean DRG-based payment system must be comprehended together with analyses of the determinants by other medical departments or higher level medical institutions.

\section{ACKNOWLEDGEMENT}

This study was supported by the Health Insurance Review and Assessment Service.

\section{REFERENCES}

1. Wennberg JE, Barnes BA, Zubkoff M. Professional uncertainty and the problem of supplier-induced demand. Soc Sci Med 1982; 16(7): 811-824.

2. Wennberg JE, McPherson K, Caper P. Will payment based on diagnosis-related groups control hospital costs? N Engl J Med 1984; 311(5): 295-330.

3. Iversen T, Luras H. The effect of capitation on GPs' referral decisions. Health Econ 2000; 9(3): 199-210

4. Ellis RP. McGuire TG. Optimal payment systems for health services. J Health Econ 1990; 9(4): 375-396

5. Huh SI, Whang DK, Jeong SH, Lee SK. Empirical Analyses of Supplier-Induced Demand from a Single-Payer System. Seoul: Korea Institute for Health and Social Affairs. 2008. (Korean)

6. Kwon S. Payment system reform for health care providers in Korea. Health Policy Plan 2003; 18(1): 84-93

7. Kim CY, Lee YS, Yoon SJ, Lee WY, Im JS, Kwon YH et al. Evaluation and Improvement Proposal on the Pilot Implementation of DRG-Based Payment System. Seoul: Department of Health Policy \& Management, Seoul National University College of Medicine. 2000. (Korean)

8. Kang GW, Lee JS, Kim Y, Ahn TS, Jung HR, Moon SJ et al. Ways for the Improvement of DRG-Based Prospective Payment System. Seoul: Health Insurance Review and Assessment Service, Chungbuk National University Industry Academic Cooperation Foundation, SNU R\&D Foundation; 2009. (Korean)

9. Sloan FA, Steinwald B. Physician participation in health insurance plans: Evidence on Blue Shield. J Hum Resour 1978; 13(2): 237-263.

10. Sloan FA, Mitchell J, Cromwell J. Physician participation in state Medicaid programs. J Hum Resour 1978; 13(Suppl): 211-245.

11. Silverstein G, Kirkman-Liff B. Physician participation in medicaid managed care. Soc Sci Med 1995; 41(3): 355-363

12. Steinwald B, Dummit LA. Hospital case-mix change: Sicker patients or DRGs creep? Health Aff 1989; 8(2): 35-47

13. National Health Insurance Corporation, Health Insurance Review and Assessment Service. 2007 National Health Insurance Statistical Yearbook. Seoul: National Health Insurance Corporation; 2007. (Korean)

14. Thornton J, Eakin BK. The utility-maximizing selfemployed physician. J Hum Resour 1997; 32(1): 98-128.

15. Campbell DM. Why do physicians in neonatal care units differ in their admission thresholds? Soc Sci Med 1984; 18(5): 365-374.

16. Eisenberg JM, Nicklin D. Use of diagnostic services by physicians in community practice. Med Care 1981; 19(3): 297-309.

17. Park WS, Kim HJ, Sohn MS, Park EC. Analysis of influencing factors on self-employed physician's income. Korean J Prev Med 1998; 31(4): 770-785. (Korean)

18. Jeong EK, Moon OR, Kim CY. A study on the practice variations according to physician characteristics. Korean $J$ Prev Med 1993; 26(4): 614-626. (Korean)

19. Lee AK, Jeong HJ. Distributional changes in physicians' medical care expenses from the National Health Insurance and its determinants after the separation of prescription and dispensing. Korean J Health Policy Adm 2004; 14(3): 2044. (Korean)

20. Wildavsky A. Choosing preferences by constructing institutions: A cultural theory of preference formation. Am Polit Sci Rev 1987; 81(1): 3-22.

21. Chun KH, Song MS. Studies on the variations of hospital use and the changes in hospital revenues of 10 KDRGs under the PPS. Korean J Health Policy Adm 1997; 7(1): 100-124. (Korean)

22. Fretts RC, Schmittdiel J, McLean FH, Usher RH, Goldman MB. Increased maternal age and the risk of fetal death. N Engl J Med 1995; 333(15): 953-957

23. Ko Y. The effect of DRG-PPS(DRG-Prospective Payment System) on provider's service uses according to the participation periods. [dissertation]. Seoul: Seoul National University: 2003 (Korean)

24. Yim J. Changes in quality of care for caesarean section after implementation of the DRG-based payment system. [dissertation]. Seoul: Seoul National University. 2001 (Korean)

25. Kim CY, Lee YS, Yoon SJ, Lee WY, Im JS, Kwon YH et al. Evaluation and Improvement Proposal on the Pilot implementation of DRG-Based Payment System. Seoul: Department of Health Policy \& Management, Seoul National University College of Medicine. 2000 (Korean)

26. Lim JY. The effect of doctor's payment method on practice behavior. Korean J Health Policy Adm 2004; 14(4): 48-74. (Korean)

27. Eisenberg JM. Physician utilization the state of research about physicians' practice patterns. Med Care 2002; 40(11): 1016-1035 